Sonic Scope: New Approaches to Audiovisual Culture

\title{
Raymond Sookram - "A \\ Horse With No Name" - In Three Memories
}

Raymond Sookram

Published on: Feb 15, 2021

DOI: $10.21428 / 66 f 840 a 4.96 b 465 c d$

License: Creative Commons Attribution 4.0 International License(CC-BY 4.0). 


\section{"A Horse With No Name" - In Three Memories}

Raymond Sookram, Goldsmiths, University of London

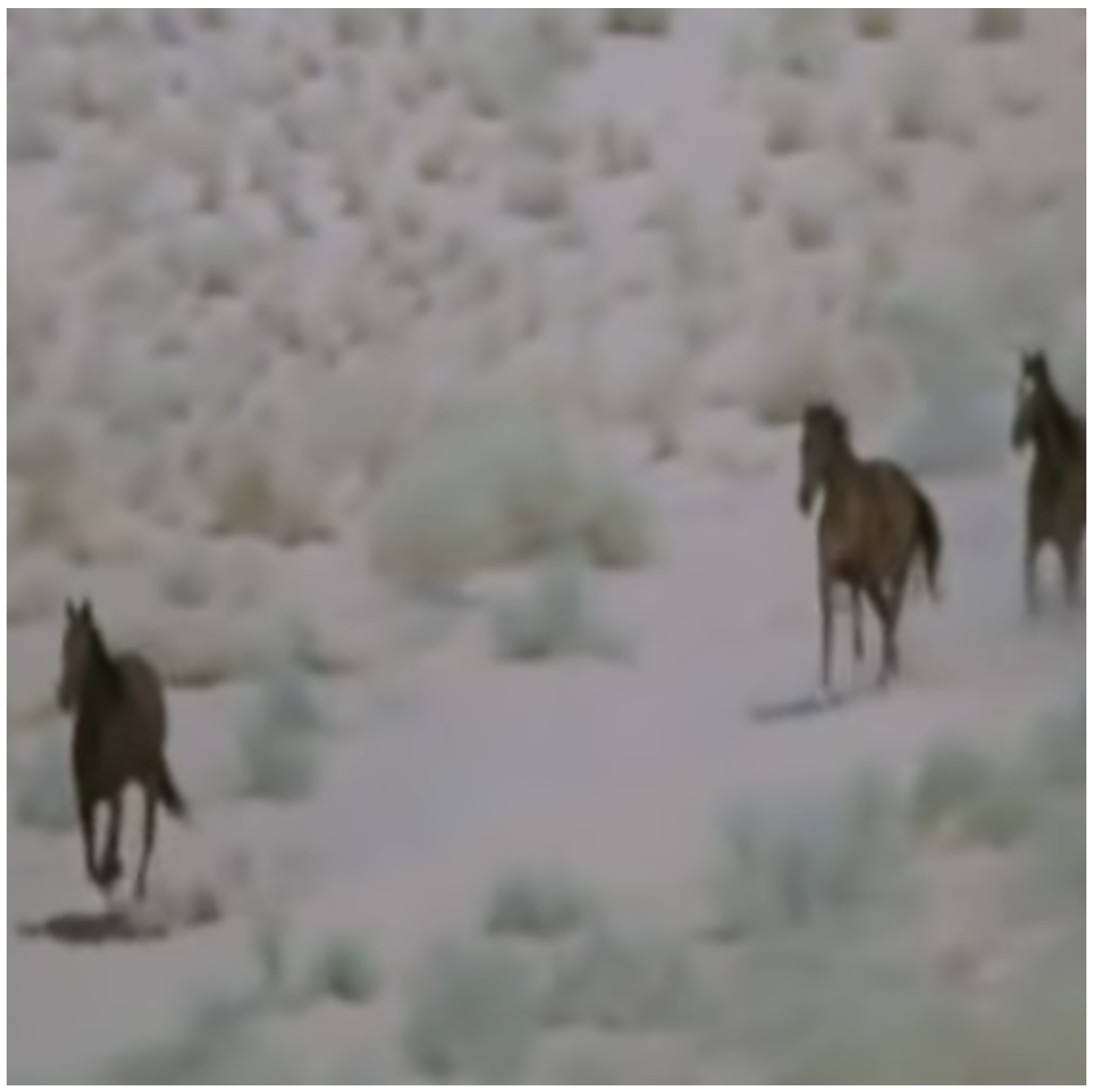

Screenshot from original music video. 3:14 in:

thesessionclubmix history, "America - A Horse With No Name ( Official Video)," November 17, 2015, accessed January 29, 2021, https://www.youtube.com/watch?v=o'EHBTjlYejE. 


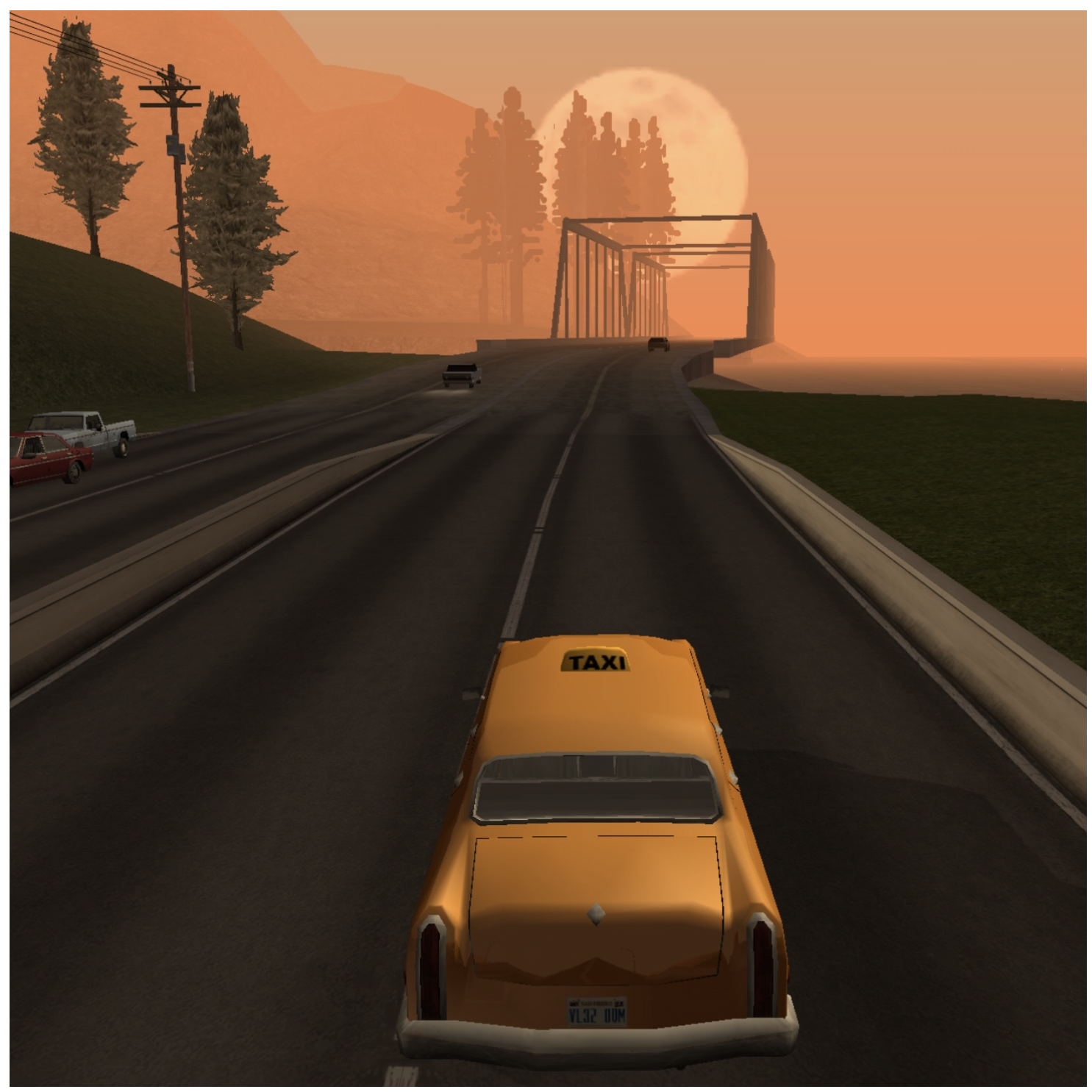

Song On Radio. Grand Theft Auto: San Andreas. Screenshot by Raymond Sookram on iPad. New York: Rockstar Games, 


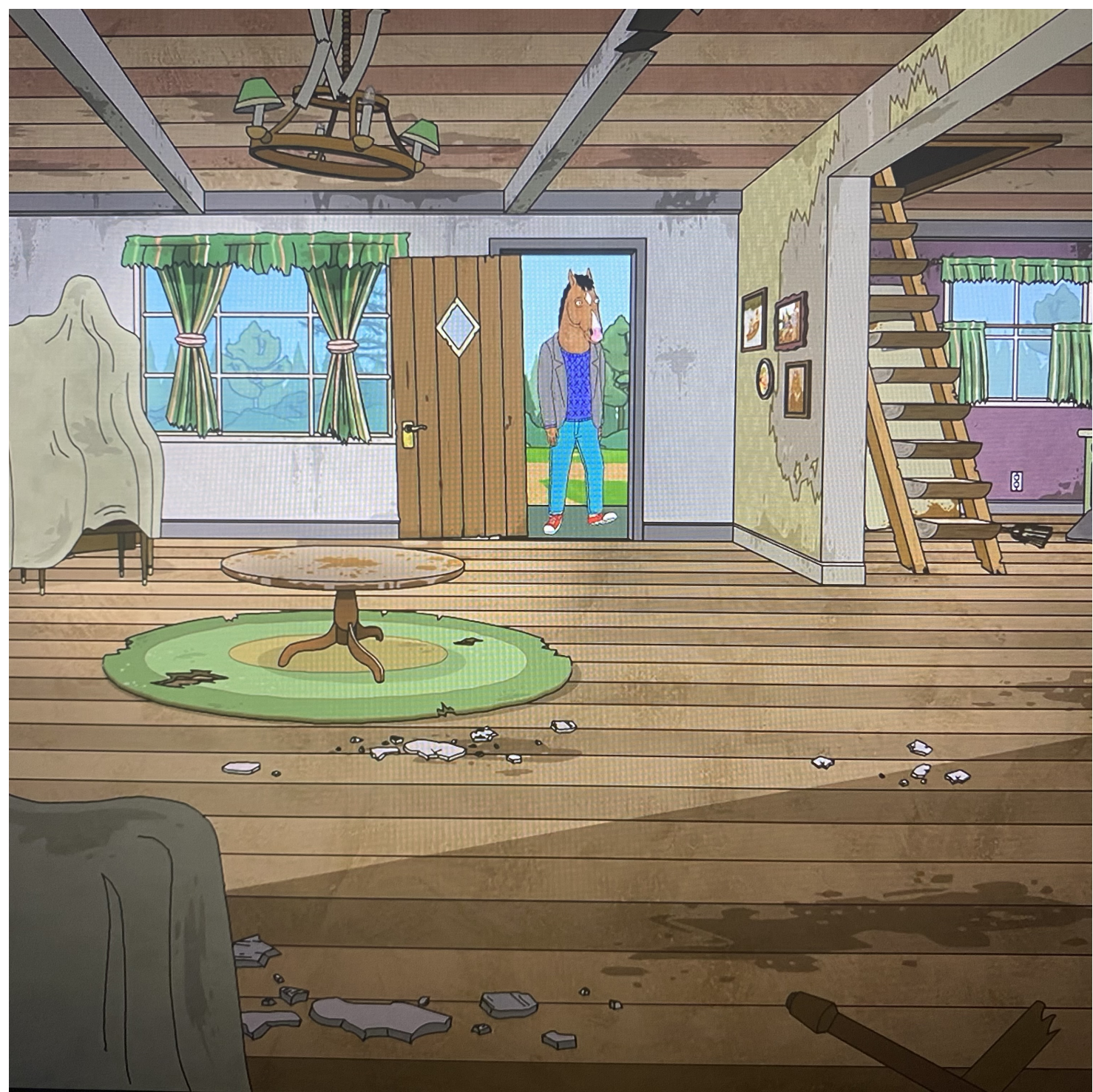

Cover Song Accompanies Bojack's Journey To His Grandparent's Home. 2:32 in

Bojack Horseman, series 4, episode 2, "The Old Sugarman Place," directed by Anne Walker Farrell, Netflix video, Los Angeles: ShadowMachine, 2017.

\section{Media Cited}

Bojack Horseman. Series 4, episode 2. “The Old Sugarman Place.” Directed by Anne Walker Farrell. Netflix video. Los Angeles: ShadowMachine, 2017.

Grand Theft Auto: San Andreas. Video game. New York: Rockstar Games, 2004. 
thesessionclubmix history, "America - A Horse With No Name ( Official Video)." YouTube video, 4:06. November 17, 2015. Accessed January 29, 2021. https://www.youtube.com/watch?v=oEHBTjIYejE. 